\title{
Genetic diversity and drug susceptibility of Mycobacterium tuberculosis in a city with a high prevalence of drug resistant tuberculosis from Southeast of Mexico
}

\author{
Roberto Zenteno-Cuevas ${ }^{1,2^{*}}$, Daniela Munro-Rojas ${ }^{4}$, Damián Pérez-Martínez ${ }^{1,3}$, Esdras Fernandez-Morales ${ }^{1,5}$, \\ Ana C. Jimenez-Ruano ${ }^{5}$, Hilda Montero ${ }^{1}$, Leila Escobar ${ }^{6}$, Everest de Igartua ${ }^{6}$, Ángel Trigos ${ }^{7}$ and \\ Javier Fuentes-Dominguez ${ }^{6}$
}

\begin{abstract}
Background: Mexico is on the top five countries with the highest number of TB cases in America continent, nevertheless, information about genotypes circulating is practically unknown. Considering the above this study aims to characterize the genetic diversity of TB in the city of Veracruz, México.

Methods: A cross-sectional study was conducted among positive smear samples from patients living in Veracruz City, samples were cultured, and first-line drug profiles determined. Genotyping was made by spoligotyping and MIRU-VNTR 24 loci. Associations of lineages, clusters, and variables were also analyzed.

Results: Among the 202 isolates analyzed resistance to at least one drug was observed in 60 (30\%) isolates and $41(20 \%)$ were multidrug-resistant. Three major lineages were identified: L4/Euro-American (88\%), L1/Indo-Oceanic (9\%), and L2/East Asian (3\%). The Euro-American lineage included more than six sublineages, the most abundant were: $\mathrm{H}(32 \%), \mathrm{T}(23 \%), \mathrm{LAM}(18 \%)$, and X (12\%). 140 isolates (70\%) were placed in 42 SITs patterns.

Conclusions: These results provide the first baseline data on the genetic structure of TB in the city of Veracruz. Sublineages $\mathrm{H}, \mathrm{X}$ and LAM were predominant; however, it was founded an important diversity of genotypes that could contribute to the dispersion of TB and explain the high prevalence. This information might be useful for the development of further interventions to reduce impact of TB.
\end{abstract}

Keywords: Spoligotyping, MIRU-VNTR, Genotyping, Tuberculosis, Mexico

\section{Background}

The World Health Organization (WHO) report describes that tuberculosis was responsible for more than 10 million cases and 1.4 million deaths in 2019, this data highlight the impact of this infectious disease [1]. In this

\footnotetext{
*Correspondence: robzencue@gmail.com

1 Public Health Institute, University of Veracruz, Av. Luis Castelazo Ayala

S/N, A.P. 57, Col. Industrial Ánimas, Xalapa, 91190 Veracruz, México

Full list of author information is available at the end of the article
}

context, in 2018 Mexico had more than 29,000 new cases of TB with an incidence of 23 per 100,000 inhabitants. The multidrug resistant/rifampicin resistant (MDR-TB /RRTB) number of cases was 950 with an incidence of 0.75 per 100,000 inhabitants, the proportion of new cases with MDR/RR was $2.6 \%$, that increases to $11 \%$ in previously treated cases [1]. These figures place Mexico in the top five countries with the highest numbers of $\mathrm{TB}$ and MDR-TB in Latin America. 
According to the official data, in 2018 Veracruz state presented near to 2400 cases of pulmonary tuberculosis; the incidence was 29 per 100,000 inhabitants, placing the state among the highest number of tuberculosis cases in the country. Specifically, Veracruz City and its metropolitan area, annually represent about $30 \%$ of the state's cases of pulmonary tuberculosis, reaching an incidence rate of 42.15 per 100,000 inhabitants, twice the national rate.

The use of molecular typing tools, such as MIRUVNTR and spoligotyping, allow the genotypic characterization of TB isolates. This information is useful to understand the population structure of $M$. tuberculosis circulating within specific regions [2,3], and identify lineages, such as Beijing, with a tendency to expand rapidly in the population or to generate drug resistance [4-7].

Information related to the genotypic characterization of tuberculosis in México is limited. Most of the reports describe the Euro-American lineage (L4) as the highest found, and to a lesser extent are lineages IndoOceanic (L1) and East Asian (L2), with important variations according to the state or city, reflecting the specific geographical and social characteristics of this disease [8-18]. Nevertheless, there are no information regards to the genotypic characteristics of the isolates circulating in Veracruz city, therefore the goal of this work is to describe the genetic structure of tuberculosis circulating in one of the cities with the highest TB prevalence in Mexico.

\section{Methods}

\section{Population and clinical sample isolation and DNA}

A total of 239 individuals living in the Veracruz City and metropolitan area, and with a confirmed acid-fast bacilli smear positive sputum specimen were included in the study. Samples were randomly recovered throughout the period April 2013 to May 2016 by the medical staff of the tuberculosis program from the Veracruz Health Department. The city of Veracruz and metropolitan area have a population close to 600,000 inhabitants.

Sputum samples were decontaminated using Petroff's modified method [19] and primary isolation was made in Lowenstein-Jensen medium. Susceptibility testing for the first-line drugs streptomycin $(\mathrm{S})$, isoniazid $(\mathrm{H})$, rifampin $(\mathrm{R})$, ethambutol $(\mathrm{E})$, and pyrazinamide $(\mathrm{Z})$ was performed using the fluorometric method (MGIT 960, Becton-Dickinson).

Variables such as age, gender, place of residence, and treatment, were recovered from the respective clinical summary of the patients. No physical interventions took place with the patients, and all information collected was anonymized and treated as confidential.
Isolation and purification of $M$. tuberculosis genomic DNA DNA isolation was done with a loop of cultured mycobacteria, following the recommendations of Van Soolingen et al. [20]. The purified DNA was dissolved in TE buffer $(10 \mathrm{mM}$ Tris-HCl, $1 \mathrm{mM}$ EDTA, $\mathrm{pH}=8.0)$ and quantified with the Nanodrop ${ }^{\mathrm{TM}} 2000$ Spectrophotometer (Thermo Fisher Scientific, Waltham, USA). The DNA samples were diluted to the required concentration and stored at $-20^{\circ} \mathrm{C}$ until use.

\section{Spoligotyping}

Spoligotyping was carried out by duplicated following standard techniques [21] using the Spoligotyping Kit (Ocimum Biosolutions, Hyderabad, India). The DNA from M. tuberculosis H37Rv and M. bovis BCG were used as controls.

Spoligotype international type (SIT) and phylogenetic clades (sublineages and families) were assigned according to the SITVIT2 http://www.pasteur-guadeloupe.fr: 8081/SITVIT2/ [22] and the similarity search module of MIRU-VNTRplus platform [23, 24]. In those isolates with not definition of SIT and lineage, the assignment was done by conformational bayesian networks $(\mathrm{CBN})$, using the online tool "TB-lineage", according authors recommendations [25]. Final lineage and sublineage assignment was done considering recommendations by Coll et al., and Stucky et al., [26, 27]. Clustering rate was calculated using the formula $(\mathrm{nc}-\mathrm{c}) / \mathrm{n}$, where the nc is the total number of clustered cases, $\mathrm{c}$ is the number of clusters, $\mathrm{n}$ is the total number of cases studied.

\section{MIRU-VNTR typing}

MIRU-VNTR analysis was carried out at 24 loci, with primers and amplification conditions according to recommendations of Supply et al. [3]. For PCR set-up, reagents from the PCR Master Mix (Promega, USA) were used. The 24-loci MIRU-VNTR fragment sizes were estimated by comparison with 100 bp DNA molecular weight ladders.

Results were independently verified by two separate individuals, and the number of repeats at each locus was calculated by applying the corresponding conversion table [28]. Twenty-four-digit MIRU-VNTR codes were by last analyzed by the MIRU-VNTRplus platform [23, 24]. The discriminatory power was measured for each locus using a calculator (https://www.hpabioinfotools.org. uk/cgi-bin/DICI/DICI.pl), based on the Hunter-Gaston Diversity Index (HGDI) [29]. According to the HGDI value, each locus was classified as highly, moderately, and poorly discriminative $(>0.6 ; 0.3<\mathrm{H}<0.6$; and $<0.3$, respectively) [30]. 


\section{Dendrogram and clustering}

The phylogenetic tree was built using data from spoligotyping and MIRU-VNTR typing data, considering the recommendations of the specific module in the MIRU-VNTRplus platform, using the UPGMA algorithm [23, 24]. Tree polar arrangement was finally done with iTol [31].

The spoligotype cluster was defined when two or more isolates sharing identical typing profile, considering the spoligotype pattern only, a relaxed cluster definition, considering differences in three markers was considered.

\section{Statistical analysis}

The patients' data were analyzed using frequencies and Chi-square statistics with Yates's correction and Fisher's exact test. With the intention of search for possible associations of some epidemiological variables (sex, age, drug resistance, etc.) with a specific SIT or cluster, respective odd ratios were calculated, considering a value of $p<0.05$ to be significant. All calculations were performed using the SPSS V.12 software.

\section{Ethical concerns}

Clinical samples were taken as part of routine diagnoses, no physical interventions took place and informed consent was obtained from all subjects, and all the information collected was treated as confidential according to national regulations and following the declaration of Helsinki. The ethics committee of the Public Health Institute at the University of Veracruz approved the ethical issues involved in this study.

\section{Results}

Demographic characteristics of the patients

Out of the 239 patients initially included in the study, positive culture grows was observed in 202 samples from the same number of individuals, which were further studied. According to gender 138 (68\%) were male. The average age was $42 \pm 15$ years old. All individuals claimed to have been born in the state and live in Veracruz City or metropolitan area for the last 10 years. Unemployment was mentioned by 25 individuals (11\%). Alcohol intake was reported by 17 individuals (8\%) (Table 1). The most frequent comorbidity was type 2 diabetes mellitus, present in 42 individuals (21\%). Eleven individuals (5\%) mentioned having had a previous TB infection, and 191 (95\%) were classified as a new case of TB.

\section{Drug resistance profiles}

Sensitivity against first-line drugs was observed in 142 isolates (67\%) and resistance to at least one first-line drug was detected in 60 isolates (30\%). Resistance to streptomycin was observed in 36 isolates (18\%), to isoniazid 52 (25\%), rifampicin 41 (20\%), ethambutol 19 (9\%) and pyrazinamide 25 (12\%). Resistance to all first-line drugs SIREP and simultaneous resistance against isoniazid and rifampicin (MDR-TB) was found in $10(12 \%)$ and 38 strains (18\%) respectively. No significant associations between some epidemiological and clinical variables and drug resistance was observed in these individuals (Table 1).

\section{Analysis of spoligotyping and clustering}

Out of 202 isolates analyzed, 86 different spoligotypes patterns were observed and 42 patterns were related with a previous SIT. By looking lineage signature by $\mathrm{CBN}$, in the isolates where was not possible to identify the

Table 1 Socio-demographic and clinical characteristics of patients with sensible and DR-TB from Veracruz city, Mexico

\begin{tabular}{|c|c|c|c|c|c|c|c|}
\hline Variable & & $\begin{array}{l}\text { Total } \\
n=202(\%)\end{array}$ & $\begin{array}{l}\text { Sensible-TB } \\
n=141 \text { (\%) }\end{array}$ & $\begin{array}{l}\text { DR-TB } \\
n=61 \text { (\%) }\end{array}$ & Fisher exact test & $p$ & $P^{*}$ \\
\hline \multirow[t]{2}{*}{ Sex } & Male & $139(68)$ & $93(65)$ & $46(75)$ & 0.246 & 0.184 & 0.245 \\
\hline & Female & $63(32)$ & $48(34)$ & $15(25)$ & & & \\
\hline \multirow[t]{3}{*}{ Age (years) } & Mean \pm SD & $42 \pm 15$ & $43 \pm 16$ & $42 \pm 14$ & 0.743 & 0.743 & 0.871 \\
\hline & $\geq 35$ & $139(68)$ & $98(70)$ & $41(67)$ & & & \\
\hline & $<35$ & $63(32)$ & $43(30)$ & $20(33)$ & & & \\
\hline \multirow[t]{2}{*}{ Alcoholism } & Yes & $17(8)$ & $14(10)$ & $3(5)$ & 0.405 & 0.255 & 0.390 \\
\hline & No & $185(92)$ & $127(90)$ & $58(95)$ & & & \\
\hline \multirow[t]{2}{*}{ T2DM comorbidity } & Yes & $42(21)$ & $34(24)$ & $8(13)$ & 0.128 & 0.089 & 0.131 \\
\hline & No & $160(79)$ & $107(52)$ & $53(87)$ & & & \\
\hline \multirow[t]{2}{*}{ HIV comorbidity } & Yes & $2(1)$ & $1(0.5)$ & $1(0.5)$ & 0.506 & 0.527 & 0.883 \\
\hline & No & $200(99)$ & $140(99.5)$ & $60(99.5)$ & & & \\
\hline
\end{tabular}

*Yates's correction 
respective SIT, it was possible to assign the sublineage in almost all isolates analyzed (Table 2).

The global analysis of the genotypes found shows the presence of three major lineages (Fig. 1): The first lineage was L1 (Indo-Oceanic), including eighteen isolates (9\%), of which ten share the spoligotype pattern and SIT 19 (L1.2, EAI2-Manila), one had the SIT 3277 and remaining seven isolates were absent of one SIT but classified by CBN as EAI2-Manila. The second lineage found was L2 (East Asian), containing six strains (3\%), three share the same spoligotype and SIT 1 (L2.2, Beijing), and remaining three isolates were classified by $\mathrm{CBN}$ as MANU2 or MANU3 (Table 2). The third lineage found was the predominant, L4 (Euro-American), including 176 strains (87\%) (Table 2). The detailed analyses show the occurrence of five major sublineages organized as follows: Sublineage X (L4.1.1) found in 25 strains (12\%) with 12 spoligotypes divided into three clades; X1, X2 and X3. Sublineage $H$ (L4.1.2), including the largest number of isolates 61 (32\%), with 21 spoligotypes, in four clades; H1, H2, H3 and H/U. Sublineage LAM (L4.3) account 37 (18\%) strains, with 14 spoligotypes, placed in five clades LAM1, LAM3, LAM4, LAM9, and LAM11. Sublineage $\mathrm{T}$ (L4.8) include 46 isolates (23\%) in 22 spoligotypes, included in the clades; T1, T2, T3, H37Rv, and T1-RUS2. By last, sublineage S (L4.4) showed the lowest frequency with four (2\%) isolates including SIT 707 and three spoligotypes, followed by sublineage Tur (L4.2.2) with two isolates (1\%) bearing the same spoligotype and SIT 41.

According to clustering by spoligotyping, 147 isolates (73\%) were placed in 31 clusters (consisting of 2-18 strains), the clustering rate was $58 \%$ (Table 3 ). Sublineage $\mathrm{H}$ included the largest number of isolates clustered, with $51(25 \%)$ strains placed in twelve clusters, the cluster L4-8 (H3, SIT 50), was the most abundant including eighteen strains (9\%). The second most abundant sublineage with isolates clustered was T, including 30 isolates (15\%) placed in four clusters, and the second most abundant cluster L4-25 (T1, SIT 53) including seventeen strains (8\%). LAM was the sublineage with the third most abundant number of isolates clustered, with twenty-seven strains, placed in five clusters, including the cluster L4-19 (LAM9, SIT 42), with fifteen (7\%) isolates (Table 3).

\section{MIRU-VNTR typing}

Of the 202 isolates analyzed only 91 were placed in 22 clusters with 24 locus MIRU-VNTR remaining, giving a clustering rate of $34 \%$. Meanwhile, considering the use of 15 locus MIRU-VNTR, 68 isolates were placed in 18 clusters, giving a clustering rate of $25 \%$ (Additional file 1 : Table S1).

According to the HGDI values MIRU QUB26 (0.85), and QUB11b (0.84) was the most discriminatory locus, mine while the least discriminatory was MIRU02 (0.35). The HGDI at each MIRU-VNTR locus varied significantly. Sixteen loci exceeded $0.6 \mathrm{~h}$, suggesting that they were highly discriminating, (2165: ETRA, 3690: Mtub39, 2531: MIRU23, 2461: ETRB, 2347: Mtub29, 1644: MIRU16, 2996: MIRU26, 3192: MIRU31, 2401: Mtub30, 802: MIRU40, 4156: QUB4156, 580: MIRU04, 960: MIRU10, 424: Mtub04, 2163b: QUB11b and 4052: QUB26). Remaining eight loci (154 MIRU02, 2059 MIRU20, 2687 MIRU24, 577 ETRC, 3171 Mtub34, 3007 MIRU27, 1955 Mtub21, and 4348 MIRU39), showed moderate discrimination $(0.3 \leq h \leq 0.6)$.

\section{Genotyping characterization of the MDR-TB isolates}

Of the 38 MDR-TB isolates identified, 28 (74\%) were placed in 15 clusters, the rest were singletons. The four sublineages with the higher number of clusters containing TB-MDR isolates were: (1) sublineage $\mathrm{X}$, with two clusters including eight MDR-TB isolates (cluster L4-29 and L4-30). (2) sublineage LAM, with seven MDRTB isolates in two clusters (cluster L4-19 and L4-18) (Table 3). No epidemiological or clinical associations with any cluster or sublineage in the MDR-TB isolates were identified.

\section{Discussion}

The present study provides the first description of the genetic structure of $M$. tuberculosis in Veracruz city and its metropolitan area. This region comprises a $1,642 \mathrm{~km}^{2}$ surface, includes 800,000 inhabitants, is bordering the Gulf of Mexico, and is the city with the most important port activity in the East of the country. The TB prevalence is 42 per 100,000 inhabitants, besides, it concentrates most of the DR and MDR-TB cases in the state, and the country. For these reasons is considered as one of the hotspot cities for TB and MDR-TB in Mexico.

Of the 202 strains studied, 61 (30\%) were resistant to at least one drug, and 38 (18\%), were multi-drug resistant, also was found that 191 individuals (95\%) were new cases. These data confirm the contribution of this region to the TB problem and the magnitude of the primary resistant transmission. Additional studies will be necessary to evaluate the factors that participating in this transmission.

At the phylogenetic level, the Euro-American lineage (L4) was predominant among isolates studied with $60 \%$. This is consistent with previous studies, in which this lineage is described as highly frequent in several regions from Mexico [8, 9, 11-17], and Latin American countries $[32,33]$. This success in the transmission of this lineage has been explained as a consequence of the European colonization, in the middle of the sixteenth century, with the importation of lineages and sublineages [26, 32, 34], and 


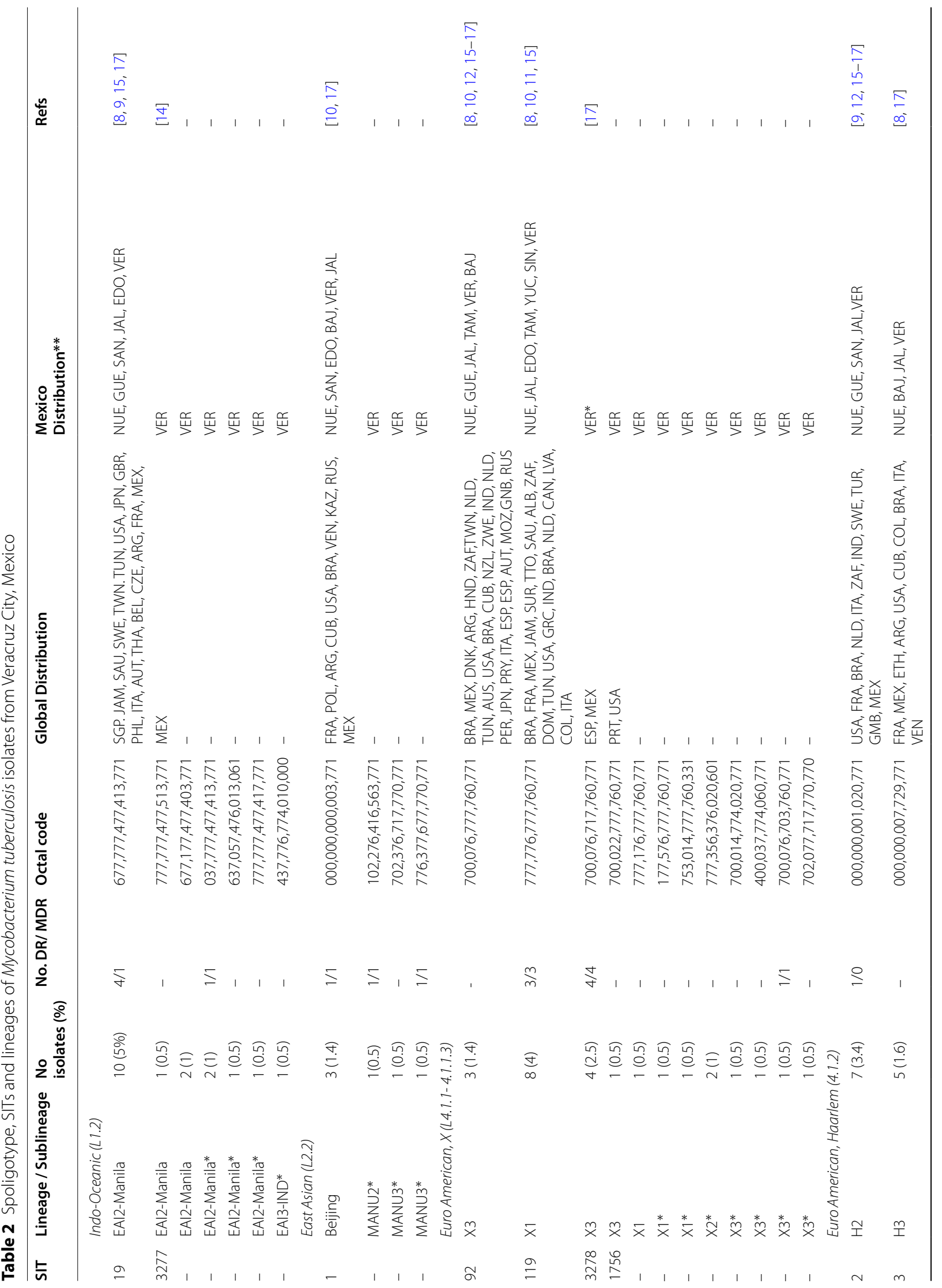




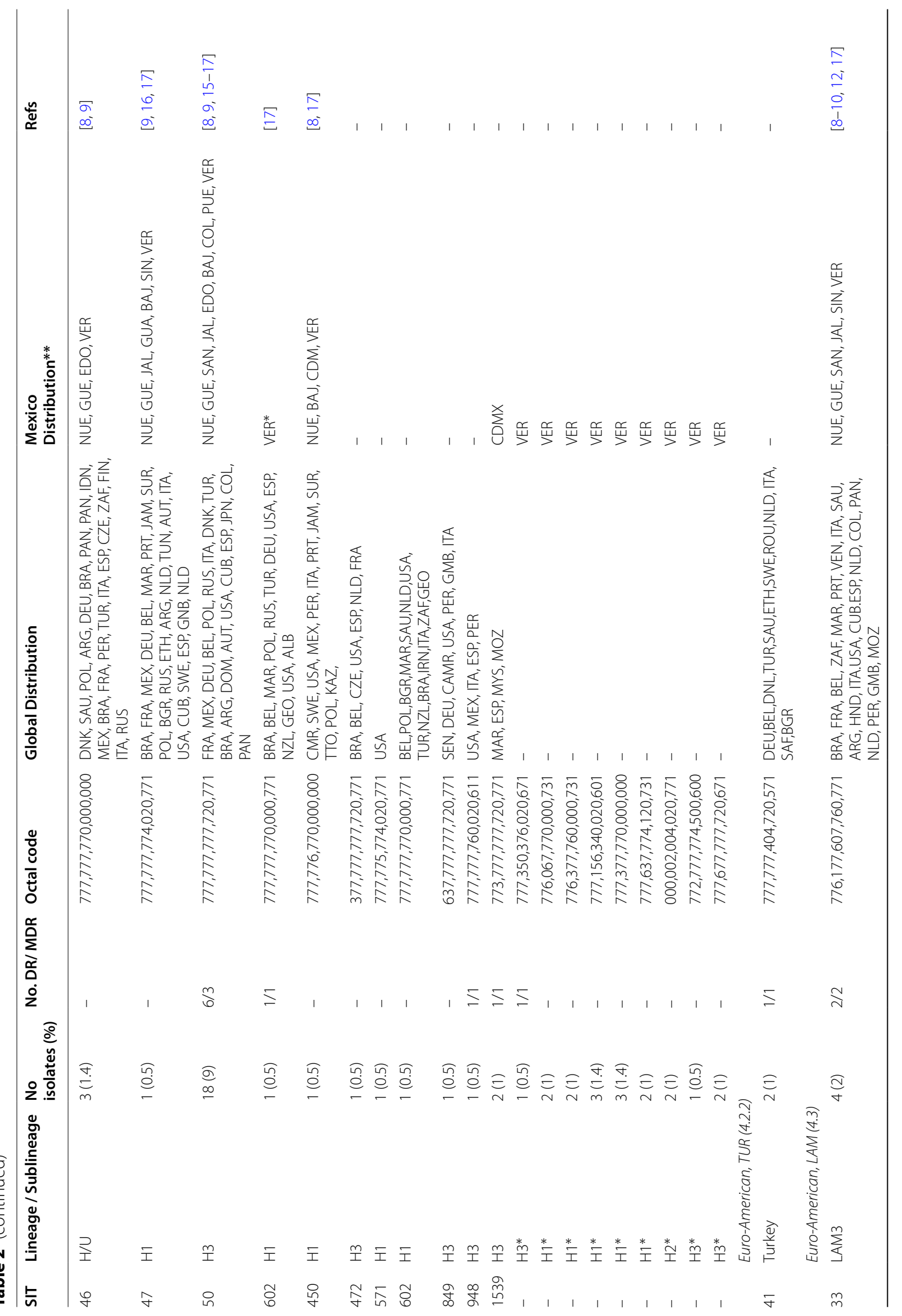




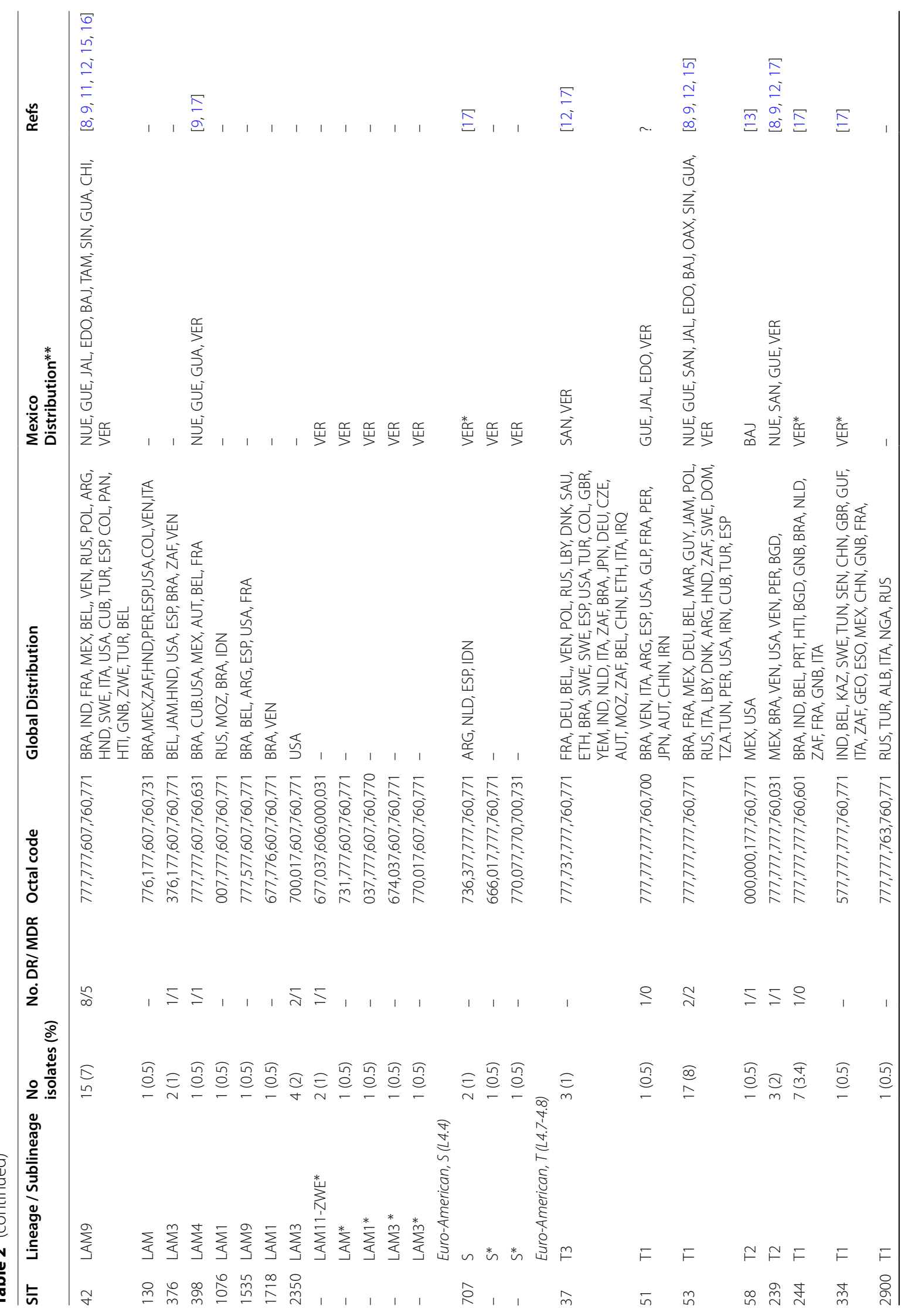




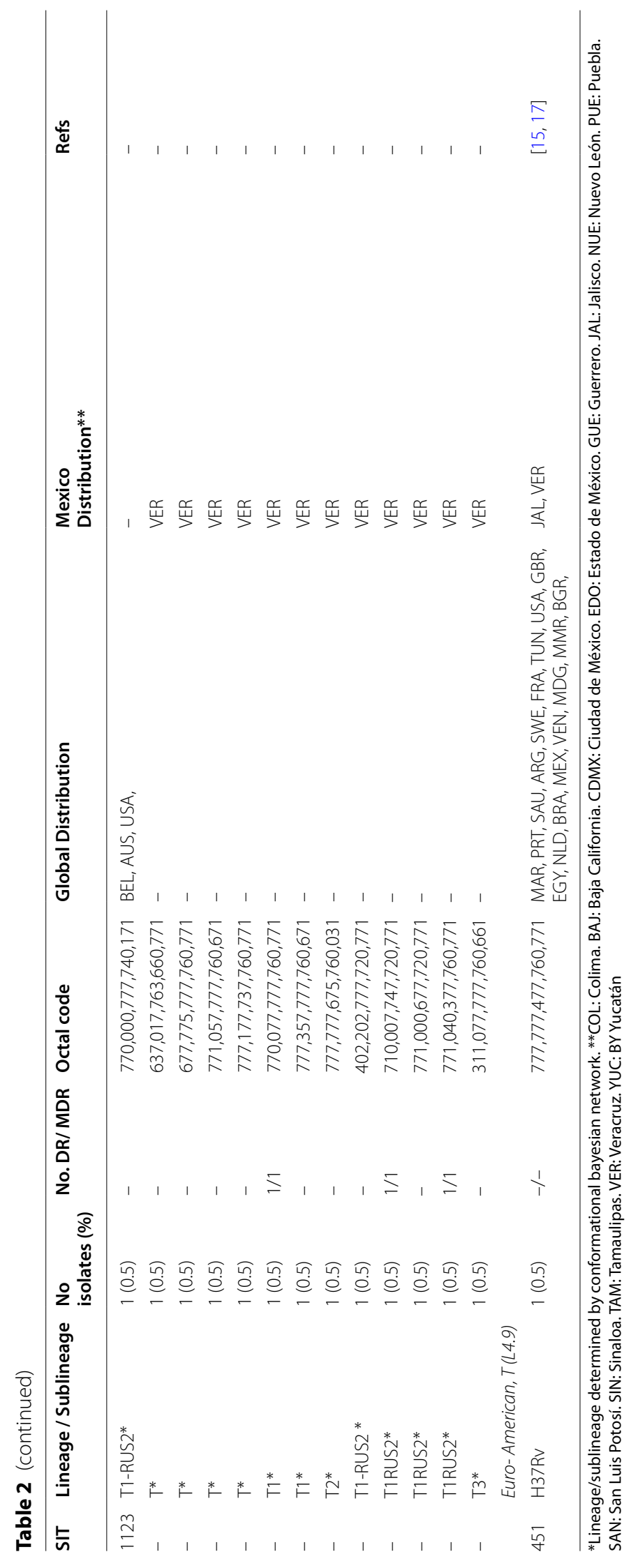




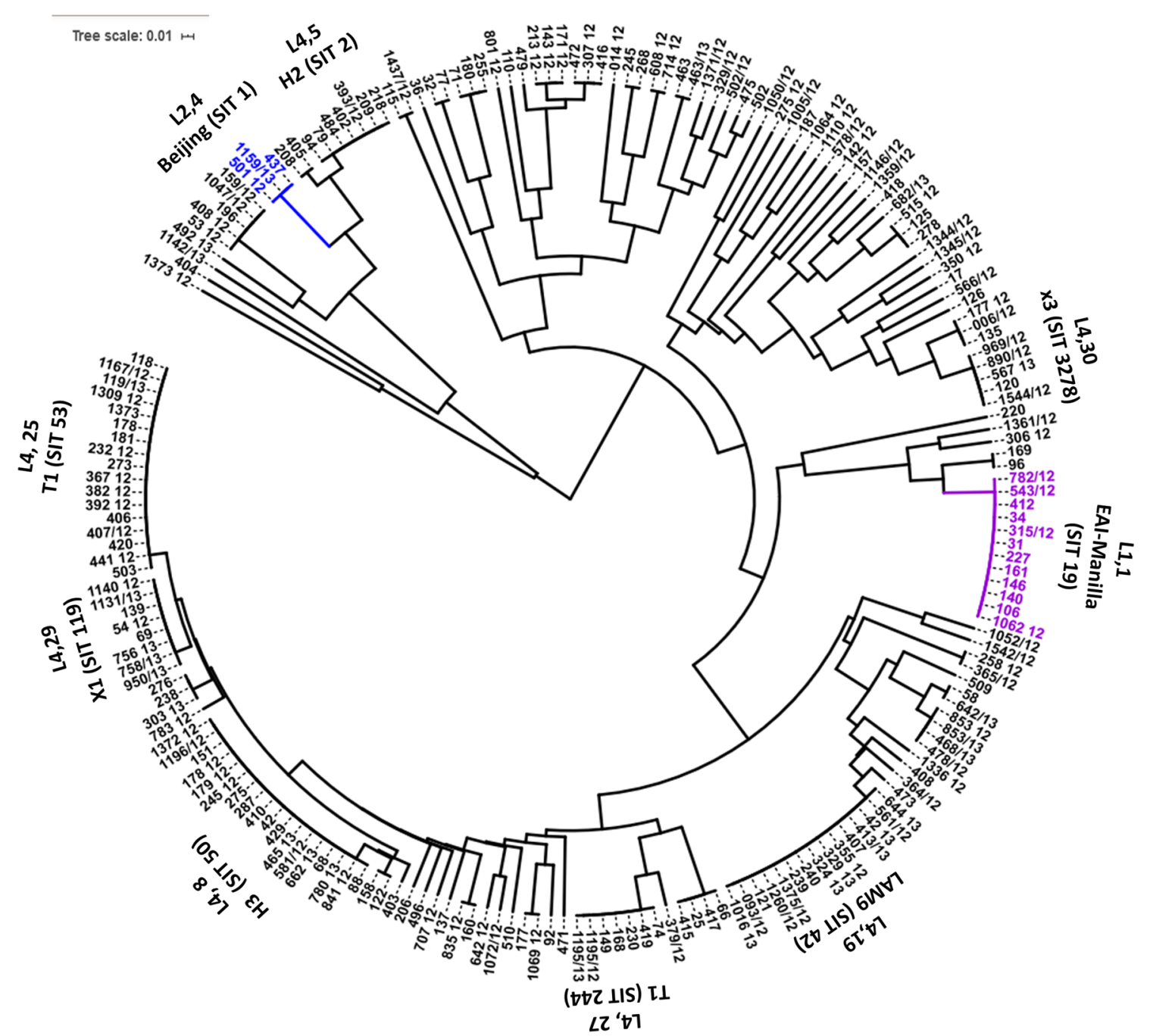

Fig. 1 Circular tree showing the genetic relationship among 202 M. tuberculosis isolates based on their corresponding spoligotype typing pattern and cluster formation

also in terms of its adaptation to the immune response of the host in the region [35].

Inside the Euro-American lineage, six sublineages were identified: $\mathrm{H}, \mathrm{LAM}, \mathrm{T}, \mathrm{X}, \mathrm{TUR}$ and $\mathrm{S}$, including fifteen groups $(\mathrm{H} 1, \mathrm{H} 2, \mathrm{H} 3$, and H/U, LAM1, LAM3, LAM4, LAM9, T1, T2, T3, h37Rv, T1-RUS, X1, X3, TUR and S). Most of these sublineages had been described in several locations of the country, confirming their role in shaping the genetic structure of $M$. tuberculosis [8-16] in Mexico.

Lineage L1 (Indo-Oceanic) was the second most abundant phylogenetic group found, comprising $9 \%$ of the strains analyzed (18).This low frequency of occurrence is in agreement with previous reports from other settings in the country, however, it is important to mention that isolates with this lineage seems to be increased in cities with important international port activities [9, 14, 16, 18]. Specifically, Veracruz City is placed bordering the Gulf of Mexico and has one of the most important seaport activities in the country, keeping important commercial, touristic, and migration activities with countries from South America, Europe, Africa, and West Asia. Therefore, the frequency of isolates with L1, and the potential association with migratory activities should be analyzed in detail considering more resolutive tools such as WGS.

The third group found was lineage L2, East Asian, including 3\% $(n=6)$ of isolates. Three isolates were considered as MANU, being the first description of these spoligotypes in the country. In addition, three isolates were classified as Beijing (SIT1), confirming that this lineage is widely distributed in the country $[12,14,16,17]$. 
Table 3 Clusters defined by spoligotyping and Tb-lineage in M. tuberculosis isolates from Veracruz city, Mexico

\begin{tabular}{|c|c|c|c|c|c|c|}
\hline $\begin{array}{c}\text { Lineage/ } \\
\text { cluster }\end{array}$ & SIT & Sublineage & $\begin{array}{c}\text { No. of isolates } \\
(\%)\end{array}$ & $\begin{array}{c}\text { No. of } \\
\text { MDR/TB }\end{array}$ & Octal code & Spoligotype description \\
\hline $\mathrm{L} 1,1$ & 19 & EAI2-Manilla & $10(5)$ & & 677777477413771 & 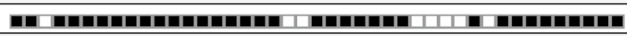 \\
\hline $\mathrm{L} 1,2 *$ & - & EAI2-MANILA & $2(1)$ & & 677177477403771 & 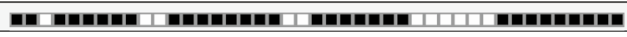 \\
\hline $\mathrm{L} 1,3 *$ & - & EAI2-MANILA & $2(1)$ & 1 & 037777477413771 & 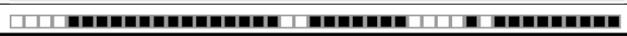 \\
\hline $\mathrm{L} 2,4$ & 1 & Beijing & $3(1.5)$ & 1 & 000000000003771 & 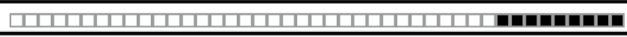 \\
\hline $\mathrm{L} 4,5$ & 2 & $\mathrm{H} 2$ & $7(3)$ & & 000000001020771 & 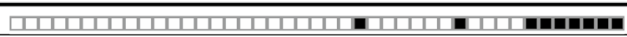 \\
\hline $\mathrm{L} 4,6$ & 3 & $\mathrm{H} 3$ & $5(2.5)$ & & 000000007729771 & 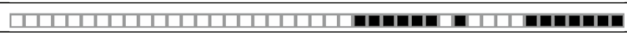 \\
\hline $\mathrm{L} 4,7$ & 46 & $\mathrm{H}$ & $3(1.5)$ & & 777777770000000 & 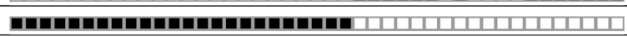 \\
\hline $\mathrm{L} 4,9$ & 1539 & $\mathrm{H} 3$ & $2(1)$ & 1 & 773777777720771 & 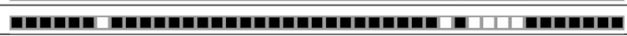 \\
\hline $\mathrm{L} 4,10^{*}$ & - & $\mathrm{H} 1$ & $2(1)$ & & 776067770000731 & 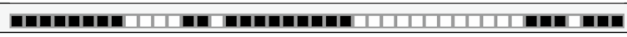 \\
\hline L4, $11 *$ & - & $\mathrm{H} 1$ & $2(1)$ & & 776377760000731 & 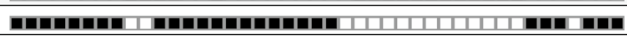 \\
\hline $\mathrm{L} 4,12^{*}$ & - & $\mathrm{H} 1$ & $3(1.5)$ & & 777156340020601 & 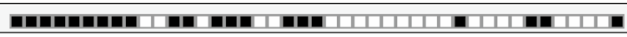 \\
\hline L4, 13* & - & $\mathrm{H} 1$ & $3(1.5)$ & & 777377770000000 & 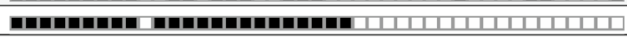 \\
\hline $\mathrm{L} 4,14 *$ & - & $\mathrm{H} 1$ & $2(1)$ & & 777637774120731 & 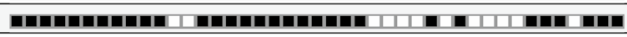 \\
\hline L4, $15^{*}$ & - & $\mathrm{H} 2$ & $2(1)$ & & 000002004020771 & 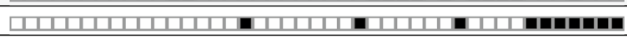 \\
\hline $\mathrm{L} 4,16^{*}$ & - & $\mathrm{H} 3$ & $2(1)$ & & 777677777720671 & 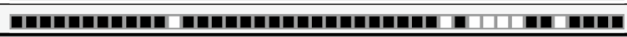 \\
\hline $\mathrm{L} 4,19$ & 42 & LAM9 & $15(7.5)$ & 5 & 777777607760771 & 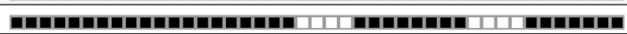 \\
\hline $\mathrm{L} 4,20$ & 376 & LAM3 & $2(1)$ & 1 & 376177607760771 & 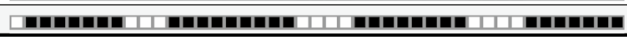 \\
\hline $\mathrm{L} 4,21$ & 2350 & LAM3 & $4(2)$ & 1 & 700017607760771 & 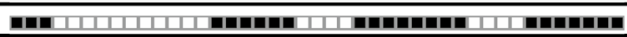 \\
\hline $\mathrm{L} 4,22 *$ & - & LAM11-ZWE & $2(1)$ & 1 & 677037606000031 & 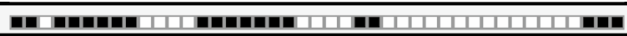 \\
\hline $\mathrm{L} 4,23$ & 707 & $\mathrm{~S}^{*}$ & $2(1)$ & & 736377777760771 & 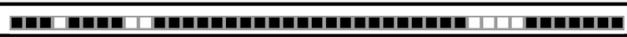 \\
\hline $\mathrm{L} 4,24$ & 37 & T3 & $3(1.5)$ & & 777737777760771 & 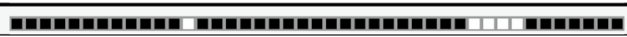 \\
\hline $\mathrm{L} 4,25$ & 53 & T1 & $17(8.5)$ & 2 & 777777777760771 & 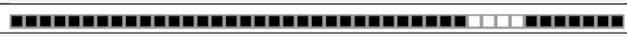 \\
\hline $\mathrm{L} 4,26$ & 239 & $\mathrm{~T} 2$ & $3(1.5)$ & 1 & 777777777760031 & 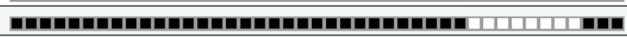 \\
\hline $\mathrm{L} 4,27$ & 244 & $\mathrm{~T} 1$ & $7(3)$ & - & 777777777760601 & 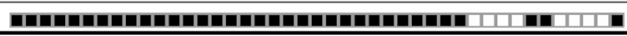 \\
\hline $\mathrm{L} 4,28$ & 92 & $\mathrm{X} 3$ & $3(1.5)$ & - & 700076777760771 & 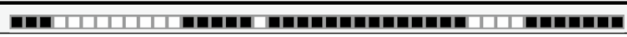 \\
\hline $\mathrm{L} 4,29$ & 119 & $\mathrm{X} 1$ & $8(4)$ & 4 & 777776777760771 & 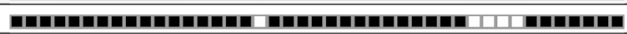 \\
\hline $\mathrm{L} 4,30$ & 3278 & $\mathrm{X} 3$ & $4(2)$ & 4 & 700076717760771 & 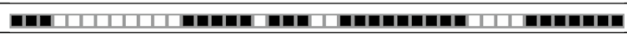 \\
\hline $\mathrm{L} 4,31^{*}$ & - & $\mathrm{X} 2$ & $2(1)$ & & 777356376020601 & 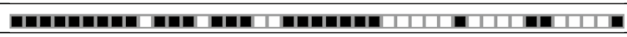 \\
\hline & & Total & $146(73 \%)$ & 28 & & \\
\hline
\end{tabular}

**Lineage/sublineage determined by CBN.

Sublineage Beijing has been documented to have higher virulence, mortality and a strong tendency to develop drug resistance, even causing up to $50 \%$ of $\mathrm{TB}$ cases in East-Asia [36]. The low frequency observed for this lineage in Veracruz city may be due to a poor adaptation to the local population or a recent introduction in the area. There is no doubt that the identification and characterization of this lineage will have important epidemiological implications in this city, so molecular epidemiological studies should be continued to identify transmission and infection routes.

Out of 202 isolates analyzed, 140 (69\%) were included in 42 spoligotype patterns with a previously reported SIT. The most abundant were SIT $50(\mathrm{H} 3, \mathrm{n}=18)$, followed by SIT $53(\mathrm{~T} 1, \mathrm{n}=17)$ and SIT 42 (LAM9, $\mathrm{n}=15)$, all these SITs have been commonly described in several states from the North, Center, and South of Mexico, and several countries from America and Europe (Table 2). These three SITs also included the $62 \%$ of DR-TB and $50 \%$ of the MDR-TB cases identified and could be considered as important participants in the transmission of $\mathrm{TB}$ in the city.

The diversity of SITs observed, the low cluster index of $58 \%$ and the important number of isolates with no previous SIT description in the country, emphasize the diversity of the genetic structure of $\mathrm{TB}$ observed in the City of Veracruz. With no doubt, the inclusion of a greater number of isolates, and the inclusion of more powerful tools of analysis, such as WGS, will help to confirm the diversity of the genotypes found, and paths of transmission. This information will help to explain with more detail, the high prevalence of $\mathrm{TB}$ in this city and the potential participation of the migration or the international trade.

An important failure of this study was the no identification of associations related to socio-demographic, clinical, and lineage conditions. The only exception was the association between resistance against pyrazinamide and clustering $(p=0.001)$ (Additional file 2: Table S2). This behavior has been frequently described in previous reports with Mexican isolates and explained in terms of the fragmentation of the sample by the occurrence of an important number of sublineages $[13,17]$. Undoubtedly, the number of isolates must be increased to generate sufficient data to identify the risk factors involved in the transmission of specific genotypes. 


\section{Conclusions}

In conclusion, this work provides, for the first time, the description of the genetic structure of $M$. tuberculosis strains circulating in a hotspot city of TB in Mexico by using spoligotyping and MIRU-VNTR-typing methods. Two were the major findings, the first related with the strong participation of Euro American lineage, accounted for over two-thirds of tubercle bacilli studied, confirming the main role of this lineage in shaping the genetic structure of TB and second was related with the high diversity of sublineages and genotypes observed in circulation.

\begin{abstract}
Abbreviations
TB: Tuberculosis; WHO: World Health Organization; DR-TB: Drug resistant tuberculosis; MDR-TB: Multidrug resistant tuberculosis; RR-TB: Rifampicin resistant tuberculosis; MIRU-VNTR: Mycobacterial interspersed repetitive units-variable number of tandem repeats; AFB: Acid Fast Bacilli; S: Streptomycin; H: Isoniazid; R: Rifampin; E: Ethambutol; Z: Pyrazinamide; BCG: Bacillus Calmette-Guerin; HGDI: Hunter-Gaston Diversity Index; UPGMA: Unweighted pair group method with arithmetic mean; SPSS: Statistical Package for the Social Sciences; SIT: Spoligotype international type.
\end{abstract}

\section{Supplementary Information}

The online version contains supplementary material available at https://doi. org/10.1186/s12879-021-06904-z.

Additional file 1: Table S1. Clonal complexes defined by MIRU-VNTR of M. tuberculosis strains from Veracruz city, México.

Additional file 2: Table S2. Sociodemographic characteristics of individuals bearing an isolate clustered and no clustered from the city of Veracruz, México.

\section{Acknowledgements}

Thanks are due to the medical staff of the Tuberculosis program of VII jurisdiction, from Veracruz, Mexico.

\section{Authors' contributions \\ These authors contributed in the conceptualization, analysis of data, writing, reviewing, and editing of manuscript: RZ-C, DP-M, HM, LE, El, AT, JF-D, These authors contributed providing study materials and methodology: RZ-C, DM-R, DP-M, EF-M, ACJ-R, LE, JF-D. All authors read and approved the final manuscript.}

\section{Funding}

D. M-R, was a CONACYT fellow number 41603, of the Doctorado en Ciencias de la Salud of Instituto de Ciencias de la Salud of the Universidad Veracruzana. E.F-M, is a Conacyt fellow number 850447 of the Maestría en Ciencias de la Salud, Instituto de Ciencias de la Salud, Universidad Veracruzana. This work was supported by Conacyt-Proyecto de desarrollo científico para atender problemas nacionales No. 213712: Desarrollo de un sistema de vigilancia epidemiológico molecular de TB.

\section{Availability of data and materials}

The datasets used and/or analyzed during the current study available from the corresponding author under request.

\section{Declarations}

Ethics approval and consent to participate

Clinical samples were taken as part of routine diagnoses, no physical interventions took place and informed consent was obtained from all subjects, and all the information collected was treated as confidential according to national regulations and following the declaration of Helsinki. The ethics committee of the Public Health Institute at the University of Veracruz approved the ethical issues involved in this study.

\section{Consent for publication}

Not applicable.

\section{Competing interests}

The authors declare no competing interests.

\section{Author details}

${ }^{1}$ Public Health Institute, University of Veracruz, Av. Luis Castelazo Ayala S/N, A.P. 57, Col. Industrial Ánimas, Xalapa, 91190 Veracruz, México. ${ }^{2}$ Multidisciplinary Research Network on Tuberculosis, Veracruz, Mexico. ${ }^{3}$ Doctorate in Health Sciences Program, Health Sciences Institute, University of Veracruz, Veracruz, Mexico. ${ }^{4}$ Anáhuac University, Xalapa, Veracruz, Mexico. ${ }^{5}$ Master of Health Science Program, Health Sciences Institute, University of Veracruz, Xalapa, Veracruz, Mexico. ${ }^{6}$ Veracruz Health Department, Veracruz, Mexico. ${ }^{7}$ Research Center in Applied Mycology, University of Veracruz, Xalapa, Veracruz, Mexico.

Received: 20 June 2021 Accepted: 17 November 2021

Published online: 30 November 2021

\section{References}

1. WHO. WHO | Global tuberculosis report 2019. Geneva: World Health Organization; 2020. 1037//0033-2909.126.1.78.

2. Kamerbeek J, Schouls L, Kolk A, van Agterveld M, van Soolingen D, Kuijper $\mathrm{S}$, et al. Simultaneous detection and strain differentiation of Mycobacterium tuberculosis for diagnosis and epidemiology. J Clin Microbiol. 1997;35:907-14.

3. Supply P, Allix C, Lesjean S, Cardoso-Oelemann M, Rusch-Gerdes S, Willery E, et al. Proposal for standardization of optimized mycobacterial interspersed repetitive unit-variable-number tandem repeat typing of Mycobacterium tuberculosis. J Clin Microbiol. 2006;44:4498-510. https:// doi.org/10.1128/JCM.01392-06.

4. Soares RO, de Macedo MB, von Groll A, da Silva PE. Mycobacterium tuberculosis belonging to family LAM and sublineage $\mathrm{RD}(\mathrm{Rio})$ : common strains in Southern Brazil for over 10 years. Braz J Microbiol. 2013;44:1251-5.

5. Tessema B, Beer J, Merker M, Emmrich F, Sack U, Rodloff AC, et al. Molecular epidemiology and transmission dynamics of Mycobacterium tuberculosis in Northwest Ethiopia: new phylogenetic lineages found in Northwest Ethiopia. BMC Infect Dis. 2013;13:131. https://doi.org/10.1186/ 1471-2334-13-131.

6. Realpe T, Correa N, Rozo JC, Ferro BE, Gomez V, Zapata E, et al. Population structure among Mycobacterium tuberculosis isolates from pulmonary tuberculosis patients in Colombia. PLoS ONE. 2014;9: e93848. https://doi. org/10.1371/journal.pone.0093848.

7. Merker M, Blin C, Mona S, Duforet-Frebourg N, Lecher S, Willery E, et al. Evolutionary history and global spread of the Mycobacterium tuberculosis Beijing lineage. Nat Genet. 2015;47:242-9. https://doi.org/10.1038/ng. 3195.

8. Molina-Torres CA, Moreno-Torres E, Ocampo-Candiani J, Rendon A, Blackwood K, Kremer K, et al. Mycobacterium tuberculosis spoligotypes in Monterrey. Mexico J Clin Microbiol. 2010;48:448-55. https://doi.org/10. 1128/JCM.01894-09.

9. Nava-Aguilera E, Lopez-Vidal Y, Harris E, Morales-Perez A, Mitchell S, Flores-Moreno M, et al. Clustering of Mycobacterium tuberculosis cases in Acapulco: spoligotyping and risk factors. Clin Dev Immunol. 2011;2011: 408375. https://doi.org/10.1155/2011/408375.

10. Macias Parra M, Kumate Rodriguez J, Arredondo Garcia JL, Lopez-Vidal Y, Castanon-Arreola M, Balandrano S, et al. Mycobacterium tuberculosis complex genotype diversity and drug resistance profiles in a pediatric population in Mexico. Tuberc Res Treat. 2011;2011: 239042. https://doi. org/10.1155/2011/239042.

11. Zenteno-Cuevas R, Mendoza-Damián F, Muñoz ICICIC, Enciso-Moreno L, Pérez-Navarro LMLM, Ramírez-Hernández MDMDMD, et al. Description of the population structure and genetic diversity of tuberculosis in Estado de México, a low prevalence setting from Mexico. APMIS. 2015;123:11622. https://doi.org/10.1111/apm.12312. 
12. López-Rocha E, Juárez-Álvarez J, Riego-Ruiz L, Enciso-Moreno L, OrtegaAguilar F, Hernández-Nieto J, et al. Genetic diversity of the Mycobacterium tuberculosis complex in San Luis Potosí. México BMC Res Notes. 2013;6:172. https://doi.org/10.1186/1756-0500-6-172.

13. Flores-López CA, Zenteno-Cuevas R, Laniado-Laborín R, Reynaud Y, García-Ortiz RA, González-Y-Merchand JA, et al. Molecular epidemiology of Mycobacterium tuberculosis in Baja California, Mexico: a result of human migration? Infect Genet Evol. 2017;55:378-83. https://doi.org/10.1016/j. meegid.2016.07.001.

14. Martinez-Guarneros A, Rastogi N, Couvin D, Escobar-Gutierrez A, Rossi LMG, Vazquez-Chacon CA, et al. Genetic diversity among multidrugresistant Mycobacterium tuberculosis strains in Mexico. Infect Genet Evol. 2013;14:434-43. https://doi.org/10.1016/j.meegid.2012.12.024.

15. Flores-Treviño S, Morfín-Otero R, Rodríguez-Noriega E, González-Díaz E, Pérez-Gómez HR, Bocanegra-García V, et al. Genetic diversity of Mycobacterium tuberculosis from Guadalajara, Mexico and identification of a rare multidrug resistant Beijing genotype. PLOS ONE. 2015;10: e0118095. https://doi.org/10.1371/journal.pone.0118095.

16. Flores-Treviño S, Mendoza-Olazarán S, Garza-González E. Drug resistance and molecular epidemiology of mycobacterium tuberculosis in Mexico: a systematic review. Salud Publica Mex. 2014;56:63-77. https://doi.org/10. 21149/spm.v56i1.7324.

17. Munro-Rojas D, Fernandez-Morales E, Zarrabal-Meza J, Martínez-Cazares MT, Parissi-Crivelli A, Fuentes-Domínguez J, et al. Genetic diversity of drug and multidrug-resistant Mycobacterium tuberculosis circulating in Veracruz, Mexico. PLoS ONE. 2018. https://doi.org/10.1371/journal.pone. 0193626.

18. Juarez-Eusebio DM, Munro-Rojas D, Muñiz-Salazar R, Laniado-Laborín R, Martinez-Guarneros JA, Flores-López CA, et al. Molecular characterization of multidrug-resistant Mycobacterium tuberculosis isolates from high prevalence tuberculosis states in Mexico. Infect Genet Evol. 2017;55:38491. https://doi.org/10.1016/j.meegid.2016.09.012.

19. Petroff SA. A new and rapid method for the isolation and cultivation of tubercle Bacilli directly from the sputum and feces. J Exp Med. 1915;21:38-42.

20. Van Soolingen D, Hermans PWM, De Haas PEW, Soll DR, Van Embden JDA. Occurrence and stability of insertion sequences in Mycobacterium tuberculosis complex strains: evaluation of an insertion sequence-dependent DNA polymorphism as a tool in the epidemiology of tuberculosis. J Clin Microbiol. 1991;29:2578-86. https://doi.org/10.1128/jcm.29.11.2578-2586. 1991.

21. Driscoll JR. Spoligotyping for molecular epidemiology of the Mycobacterium tuberculosis complex. Methods Mol Biol. 2009;551:117-28. https:// doi.org/10.1007/978-1-60327-999-4_10.

22. Couvin D, David A, Zozio T, Rastogi N. Macro-geographical specificities of the prevailing tuberculosis epidemic as seen through SITVIT2, an updated version of the Mycobacterium tuberculosis genotyping database. Infect Genet Evol. 2018;1-13. https://www.sciencedirect.com/scien ce/article/pii/S1567134818309699?via\%3Dihub. Accessed 12 Apr 2019.

23. Weniger T, Krawczyk J, Supply P, Niemann S, Harmsen D. MIRU-VNTRplus: a web tool for polyphasic genotyping of Mycobacterium tuberculosis complex bacteria. Nucleic Acids Res. 2010;38(SUPPL. 2):W326-31. https:// doi.org/10.1093/nar/gkg351.

24. Allix-Béguec C, Harmsen D, Weniger T, Supply P, Niemann S. Evaluation and strategy for use of MIRU-VNTRplus, a multifunctional database for online analysis of genotyping data and phylogenetic identification of Mycobacterium tuberculosis complex isolates. J Clin Microbiol. 2008;46:2692-9. https://doi.org/10.1128/JCM.00540-08.

25. Shabbeer A, Cowan LS, Ozcaglar C, Rastogi N, Vandenberg SL, Yener B, et al. TB-Lineage: an online tool for classification and analysis of strains of Mycobacterium tuberculosis complex. Infect Genet Evol. 2012;12:789-97. https://doi.org/10.1016/j.meegid.2012.02.010.

26. Stucki D, Brites D, Jeljeli L, Coscolla M, Liu Q, Trauner A, et al. Mycobacterium tuberculosis lineage 4 comprises globally distributed and geographically restricted sublineages. Nat Genet. 2016;48:1535-43. https://doi.org/ 10.1038/ng.3704.

27. Coll F, McNerney R, Guerra-Assunção JA, Glynn JR, Perdigão J, Viveiros M, et al. A robust SNP barcode for typing Mycobacterium tuberculosis complex strains. Nat Commun. 2014;5:4-8. https://doi.org/10.1038/ncomm s5812.
28. Supply P. Multilocus variable number tandem repeat genotyping of Mycobacterium tuberculosis: TEchnical Guide. 2005::74.

29. Hunter PR, Gaston MA. Numerical index of the discriminatory ability of typing systems: an application of Simpson's index of diversity. J Clin Microbiol. 1988;26:2465-6.

30. Sola C, Filliol I, Legrand E, Lesjean S, Locht C, Supply P, et al. Genotyping of the Mycobacterium tuberculosis complex using MIRUs: association with VNTR and spoligotyping for molecular epidemiology and evolutionary genetics. Infect Genet Evol. 2003;3:125-33.

31. Letunic I, Bork P. Interactive Tree of Life (iTOL) v4: recent updates and new developments. Nucleic Acids Res. 2019. https://doi.org/10.1093/nar/ gkz239.

32. Wiens KE, Woyczynski LP, Ledesma JR, Ross JM, Zenteno-Cuevas R, Goodridge A, et al. Global variation in bacterial strains that cause tuberculosis disease: a systematic review and meta-analysis. BMC Med. 2018;16:196. https://doi.org/10.1186/s12916-018-1180-x.

33. Woodman M, Haeusler IL, Grandjean L. Tuberculosis genetic epidemiology: a Latin American perspective. Genes. 2019. https://doi.org/10.3390/ genes 10010053.

34. Comas I, Coscolla M, Luo T, Borrell S, Holt KE, Kato-Maeda M, et al. Out-ofAfrica migration and Neolithic coexpansion of Mycobacterium tuberculosis with modern humans. Nat Genet. 2013;45:1176-82. https://doi.org/10. 1038/ng.2744.

35. Coscolla M, Gagneux S. Consequences of genomic diversity in Mycobacterium tuberculosis. Semin Immunol. 2014;26:431-44. https://doi.org/10. 1016/j.smim.2014.09.012.

36. Parwati I, van Crevel R, van Soolingen D. Possible underlying mechanisms for successful emergence of the Mycobacterium tuberculosis Beijing genotype strains. Lancet Infect Dis. 2010;10:103-11. https://doi.org/10.1016/ S1473-3099(09)70330-5.

\section{Publisher's Note}

Springer Nature remains neutral with regard to jurisdictional claims in published maps and institutional affiliations.

Ready to submit your research? Choose BMC and benefit from:

- fast, convenient online submission

- thorough peer review by experienced researchers in your field

- rapid publication on acceptance

- support for research data, including large and complex data types

- gold Open Access which fosters wider collaboration and increased citations

- maximum visibility for your research: over $100 \mathrm{M}$ website views per year

At BMC, research is always in progress.

Learn more biomedcentral.com/submissions 